\title{
Conf- $950739-2$
}

FAILURE ANALYSIS OF AN $\alpha$-SiC TUBE SUBJECTED TO THERMAL CYCLING IN AN OXYGEN-STEAM ATMOSPHERE*

Kristin Breder and James R. Keiser

Metals and Ceramic Division

Oak Ridge National Laboratory

Oak Ridge, TN 37831-6069
PECEIVED

DEC U \& 1395

\section{ABSTRACT}

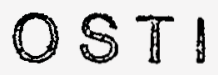

Failure analysis of a $0.965 \mathrm{~m}$ long closed end $\alpha$-SiC tube which failed during thermal cycling in an oxygen-steam atmosphere was conducted. The tube failed during heating after having survived several cycles. The shattered tube was re-assembled and the fracture origin was determined to be a flaw in the lower part of the tube on the outer surface. The flaw was likely an oxidation pit produced during the previous cycles. The stresses in the tube at the time of failure were a combination of stresses from the internal pressure and from thermal gradients.

\section{INTRODUCTION}

Oak Ridge National Laboratory (ORNL) is participating in an industry led effort to develop an advanced high pressure heat exchanger for convective steam methane reformer. The heat exchanger is utilizes ceramic tubes in an effort to raise the temperature and subsequently the effectiveness of the system and thereby reduce the energy consumption. As part of this project two experimental furnaces which can reach temperatures up to $1550^{\circ} \mathrm{C}$ and accommodate large test tubes have been constructed at ORNL. The purpose of the experimental work has been to expose candidate tubes to temperatures and environments as close to reality as possible, while carefully monitoring the temperature and pressure.

During a test cycle one of the tubes failed catastrophically. The purpose of the present failure analysis was to locate the failure initiation point and from the nature of the initiation point draw a conclusion about the failure event and the reason why the tube failed.

\footnotetext{
* Research sponsored by the U. S. Department of Energy, Assistant Secretary for Energy Efficiency and Renewable Energy, Office of Industrial Technologies, Industrial Energy Efficiency Division, under contract DE-AC05-84OR21400 with Martin Marietta Energy Systems Inc.
}

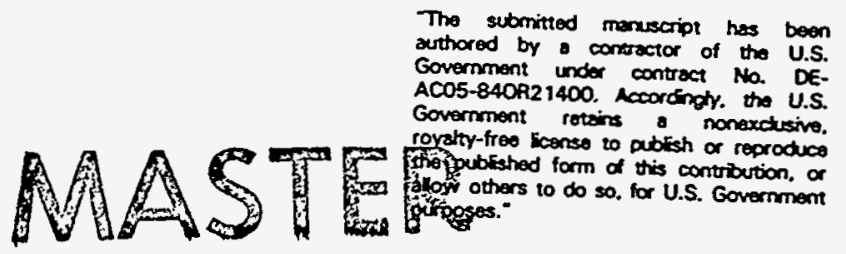




\section{EXPERIMENTAL HISTORY}

The test tubes were made of $\alpha$-SiC from Carborundum (Hexoloy SA) which is a pressureless sintered ceramic with boron as a sintering aid. This material has a room temperature strength of about $460 \mathrm{MPa}$ and this strength level is retained up to $1400^{\circ} \mathrm{C}^{1}$. Typical fracture toughness is $3-5 \mathrm{MPa} \sqrt{\mathrm{m}}$ and density is $3.1 \mathrm{~g} / \mathrm{cm}^{3}$. The material is a good candidate for heat exchangers because of its good thermal properties and relatively high resistance to thermal shock. The tubes were $0.965 \mathrm{~m}$ long with an inner diameter of $76.2 \mathrm{~mm}$ (3") and an outer diameter of $88.9 \mathrm{~mm}\left(3.5^{\prime \prime}\right)$, and had a flange at the open top end and a hemispherical closed bottom end. The tubes were hung in the furnace by fitting the flange into a steel collar. The steel collar also functioned as a lid with metal tubes coming through to the inside of the $\mathrm{SiC}$ tube for pressurizing and flush through of gas. About one third of the tube was entirely inside the furnace, one third was surrounded by an insulation lid and one third was above the furnace. The furnace was heated by $\mathrm{SiC}$ resistance heaters mounted horizontally in two opposite walls of the fumace.

Before the start of the experiment the tubes were all pressurized individually at room temperature and at $1260^{\circ} \mathrm{C}$ as a proof test measure. The tube in question was pressurized three times at room temperature up to $2 \mathrm{MPa}$ ( $300 \mathrm{psi}$ ) for a total duration of $254 \mathrm{~h}$, and twice at $1260^{\circ} \mathrm{C} ; 0.4 \mathrm{MPa}(56 \mathrm{psi})$ for $5 \mathrm{~h}$ and $2 \mathrm{MPa}(300 \mathrm{psi})$ for $18 \mathrm{~h}$. The tubes were then subjected to cycles of heat and steam pressure as described in Table I. Upon heating in the ninth cycle, one of the tubes failed catastrophically and the furnace was automatically shut down. At the time of failure only one tube was in the furnace, and the temperature was at $755^{\circ} \mathrm{C}$. The fracture event was sudden and high in energy as evidenced by an abrupt loss of pressure and the subsequent damage seen inside the furnace, see Fig 1 .

Table I. Test history of Hexoloy $\alpha$-SiC tube.

\begin{tabular}{llllll}
\hline Run No. & \multicolumn{2}{l}{$\begin{array}{l}\text { Max } \\
\text { PPassure }\end{array}$} & $\begin{array}{l}\text { Max. Temp. } \\
\text { (psi) }\end{array}$ & $\begin{array}{l}\text { C } \\
\text { hime at Temp. }\end{array}$ & $\begin{array}{l}\text { Heat-up Time } \\
\text { h }\end{array}$ \\
\hline SS-1 & 1.3 & $(198)$ & 1177 & 24 & 6 \\
SS-2 & 1.4 & $(201)$ & 1177 & 24 & 8 \\
SS-3 & 1.4 & $(200)$ & 1177 & 48 & 8 \\
SS-4 & 1.3 & $(183)$ & 1177 & 48 & 8 \\
SS-5 & 1.4 & $(201)$ & 1260 & 50 & 10 \\
SS-6 & 1.5 & $(211)$ & 1260 & 50 & 10 \\
SS-7 & 1.5 & $(216)$ & 1177 & 50 & 10 \\
SS-8 & 1.5 & $(216)$ & 1177 & 50 & 10 \\
SS-9* & {$[1.4$} & $(200)]$ & {$[1038]$} & & \\
\hline
\end{tabular}

* Did not reach operating conditions

+ Cool-down time was in addition to these times

\section{DISCLAIMER}

This report was prepared as an account of work sponsored by an agency of the United States Government. Neither the United States Government nor any agency thereof, nor any of their employees, makes any warranty, express or implied, or assumes any legal liability or responsibility for the accuracy, completeness, or usefulness of any information, apparatus, product, or process disclosed, or represents that its use would not infringe privately owned rights. Reference herein to any specific commercial product, process, or service by trade name, trademark, manufacturer, or otherwise does not necessarily constitute or imply its endorsement, recommendation, or favoring by the United States Government or any agency thereof. The views and opinions of authors expressed herein do not necessarily state or reflect those of the United States Government or any agency thereof. 




Figure 1. The furnace insulation and heating rods were damaged during the tube failure.

\section{FAILURE ANALYSIS}

The hundreds of pieces of the fractured tube were carefully collected from the furnace and the tube reassembled. Most of the tube could be put back together, except for the area right below the flange which had shattered into very small pieces, probably by impact with the steel hardware of the furnace. The reassembled tube is shown in Fig. 2 a) - c). There are several things that can be learned from studying the macro-pattern of the fractured tube. First, the overall reassembled tube indicates that the failure must have initiated in the bottom part. If the initiation had happened in the top, the bottom would not have been so shattered, and further with the lower end having smaller pieces indicating a large stored elastic energy here right before the explosion. Also, the tube pieces retrieved from the furnace were partially found in the side walls, indicating that they had been thrown horizontally rather than vertically down. Second, fracture initiating from internal pressure and also from bending and torsion typically has the fracture origin at a straight line before branching occurs. The angle between the crack branches can give an indication of the stress state, with equibiaxial tension resulting in large angles and torsion resulting in small angles. 2 These types of fracture patterns can be seen several places in the lower end of the tube. Third, several long and wavy cracks can be seen in Fig. 2 c). These are indicative of slower moving fracture typically resulting from thermal stresses. 
These are also lower in energy and it is reasonable to assume that these cracks are secondary to the energy rich cracks and occurred after the failure event had been initiated. The direction and also to some degree the velocity with which cracks move can be found from studying the Wallner lines which are curved markings on the fragment edges. ${ }^{2}$ The crack has moved in the direction of convex curvature, and the Wallner lines can therefore give indication as to where cracks might have been traveling from, i.e. ideally one could find one place where all cracks had traveled outward from a common origin.

There are a few areas of the tube which have a fracture branching pattern typical of a fracture initiation site. A longer distance before branching starts is an indication of a larger fracture initiating flaw, and hence, a lower stress would be needed to initiate failure. An empirical relationship between the fracture stress and the branching radius has been developed: 3

$$
\sigma \mathrm{r}^{1 / 2}=\mathrm{M}
$$

where $\sigma$ is the fracture stress, $r$ is half the length of the unbranched portion of the crack, and $M$ is a material and environment constant. By applying this it is possible to estimate the fracture stress for the initiation of the explosion. Then having an estimate of the stress level it is possible to estimate the flaw size at the initiation point by using the analysis of Newman and Raju: ${ }^{4}$

$$
\mathrm{K}_{\mathrm{IC}}=\frac{\mathrm{F}^{2}}{\mathrm{Q}} \sigma \sqrt{\pi \mathrm{a}}
$$

where $Q$ and $F$ are functions of the flaw dimensions and flaw and specimen dimensions respectively, KIC is the fracture toughness and the flaw depth. By assuming a semielliptical flaw in an "infinite" specimen the functions take on the specific values of: 5

$$
\mathrm{Q}=\frac{\pi^{2}}{4} \text { and } \mathrm{F}=1.144
$$

This way it is possible to make an evaluation of the flaw size one will be looking for and this will greatly aid the microscopic part of the failure analysis.

Four fragments were studied in the scanning electron microscope (SEM): two from possible initiation points, one from a fragment that had a rough zone close to the inner surface, and one with a "clean" fracture surface. These fragments are marked in Fig. 2 c). X-ray analyses on these surfaces were performed in the SEM.*

\footnotetext{
* Hitachi SEM S 800, with Tracor Northern XRD
} 

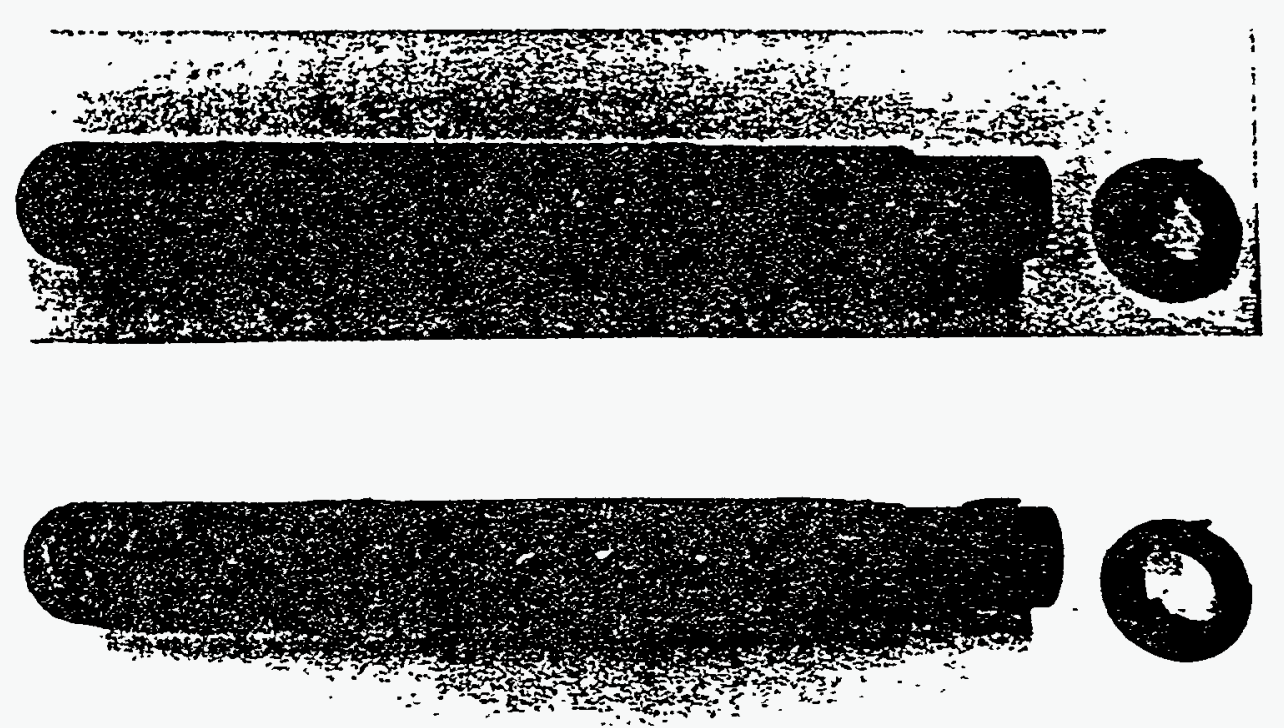



Figure $2 \mathrm{a}$ ) and b) The re-assembled tube viewed from two different sides.

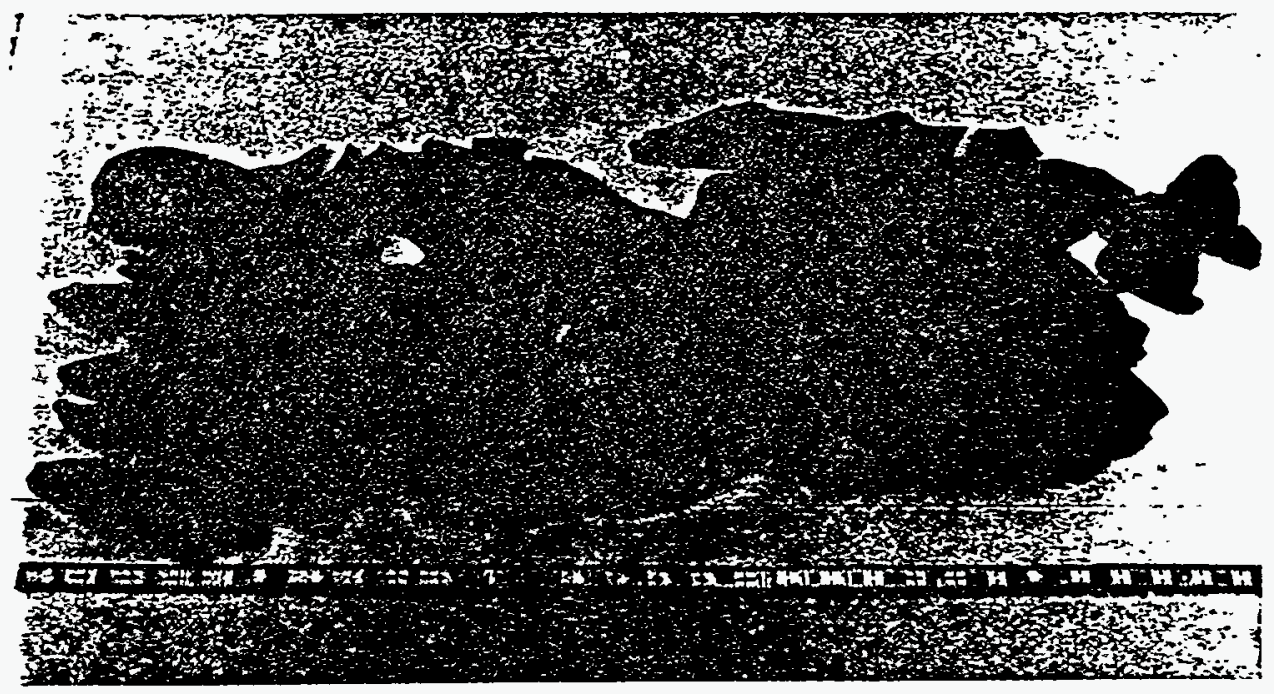

Figure 2 c) The re-assembled tube as opened up to view the pieces. 
Fragment 1, a possible initiation point, was located $170 \mathrm{~mm}$ from the bottom of the tube and had a branching length of $2 \mathrm{r}=32 \mathrm{~mm}$. Using Eq. 1 with $\mathrm{r}=16 \mathrm{~mm}$ and $\mathrm{M}=9.77 \mathrm{MPa} \sqrt{\mathrm{m}}$ for sintered $\mathrm{SiC}^{6}$ results in a calculated stress at failure of $77.2 \mathrm{MPa}$. Then, using $\mathrm{Eq} .2$ with the given values of $\mathrm{F}$ and $\mathrm{Q}$ and $\mathrm{K}_{\mathrm{IC}}=3.5 \mathrm{MPa} \sqrt{\mathrm{m}}$ it is found that the fracture initiating flaw must have had a depth of $0.9 \mathrm{~mm}$. As can be seen from Fig. 3 a) this particular fragment had a relatively large $(1.5 \mathrm{~mm})$ area which had microcracks and something that looked like oxidized material. The depth of the area can be estimated from the micrographs to be of the order $800 \mu \mathrm{m}$, close to the size calculated above. The $\mathrm{X}$-ray analysis showed that there was oxygen present in the areas which look like they have a smaller and different grain size than the rest of the surface. (Fig. $3 \mathrm{~b}$, and c).

Fragment 2, a "clean" surface shown in Fig. 4 was analyzed for comparison. The X-ray pattern for this showed, as expected, basically $\mathrm{SiC}$.

Fragment 3 had a surface with some irregularities to it, and was picked for that reason. This showed no oxidation, but had several small cracks going parallel to the surface, see Fig. 5. It is difficult to say whether these were produced by the overall fracture event or not, but it is not likely that they were there in the as-received tube. X-ray analysis from this area showed no evidence of oxygen.

Fragment 4 was from another possible initiation point. This had a crack branching length of the same order of magnitude as Fragment 1 and should therefore contain a flaw of the same order of magnitude as described above. As can be seen from Fig. 6 this had a large crevasse - like crack which extended into a closed up crack. This was located somewhat down into the material but seemed to be connected to the surface. The X-ray analysis showed a possible presence of oxygen inside this crack. The unusual "bridge" seen in Fig. 6 is an indication that this is a complicated fracture event and that part of this crack existed before the catastrophic failure occurred. The SEM analysis gave, however, no indication that this could have been a pore existing from the beginning, because the grain morphology in a pore is distinctively different from that produced by fracture. 


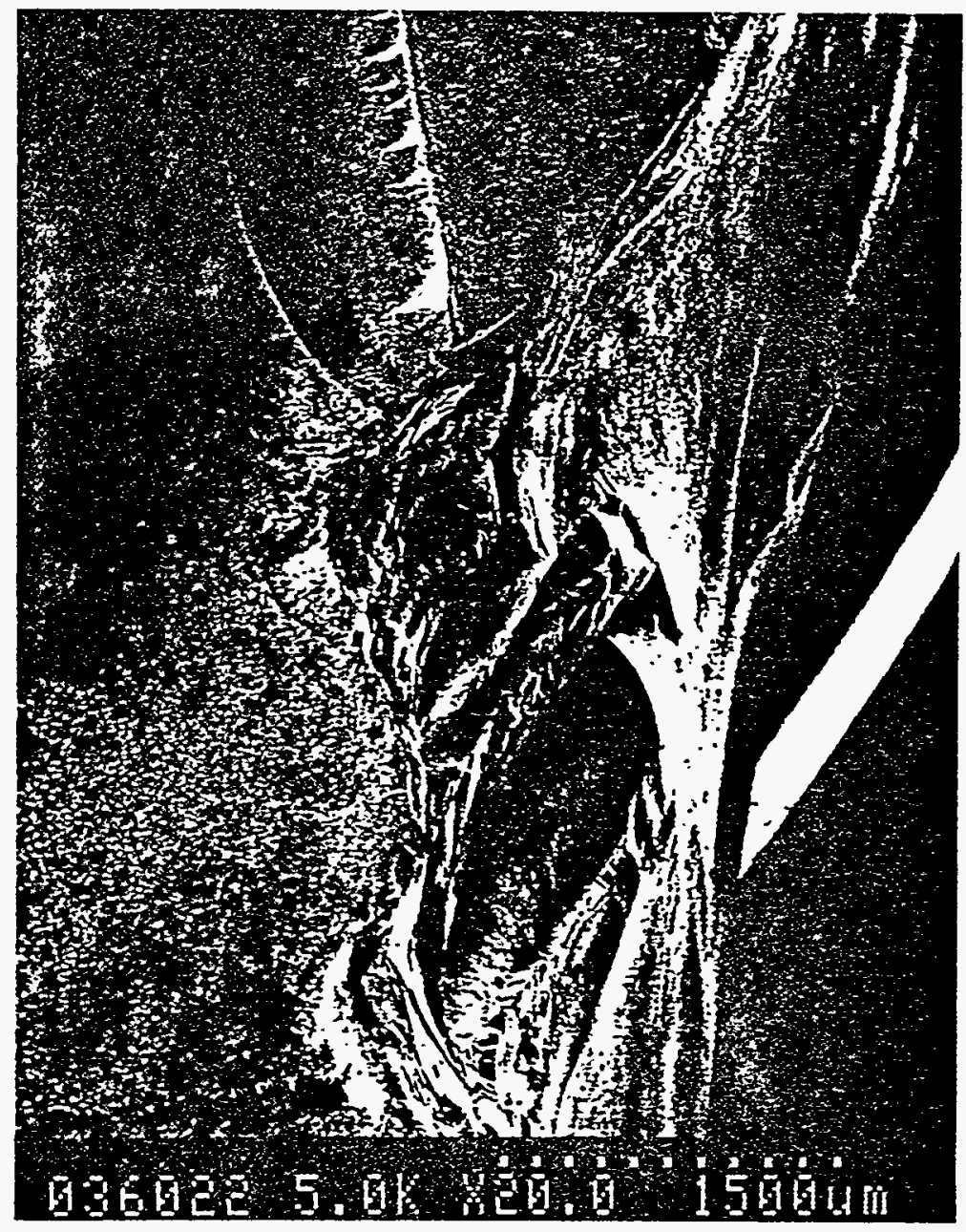

Figure 3. a) Possible fracture origin from fragment \#1 in Fig. 2 c). 


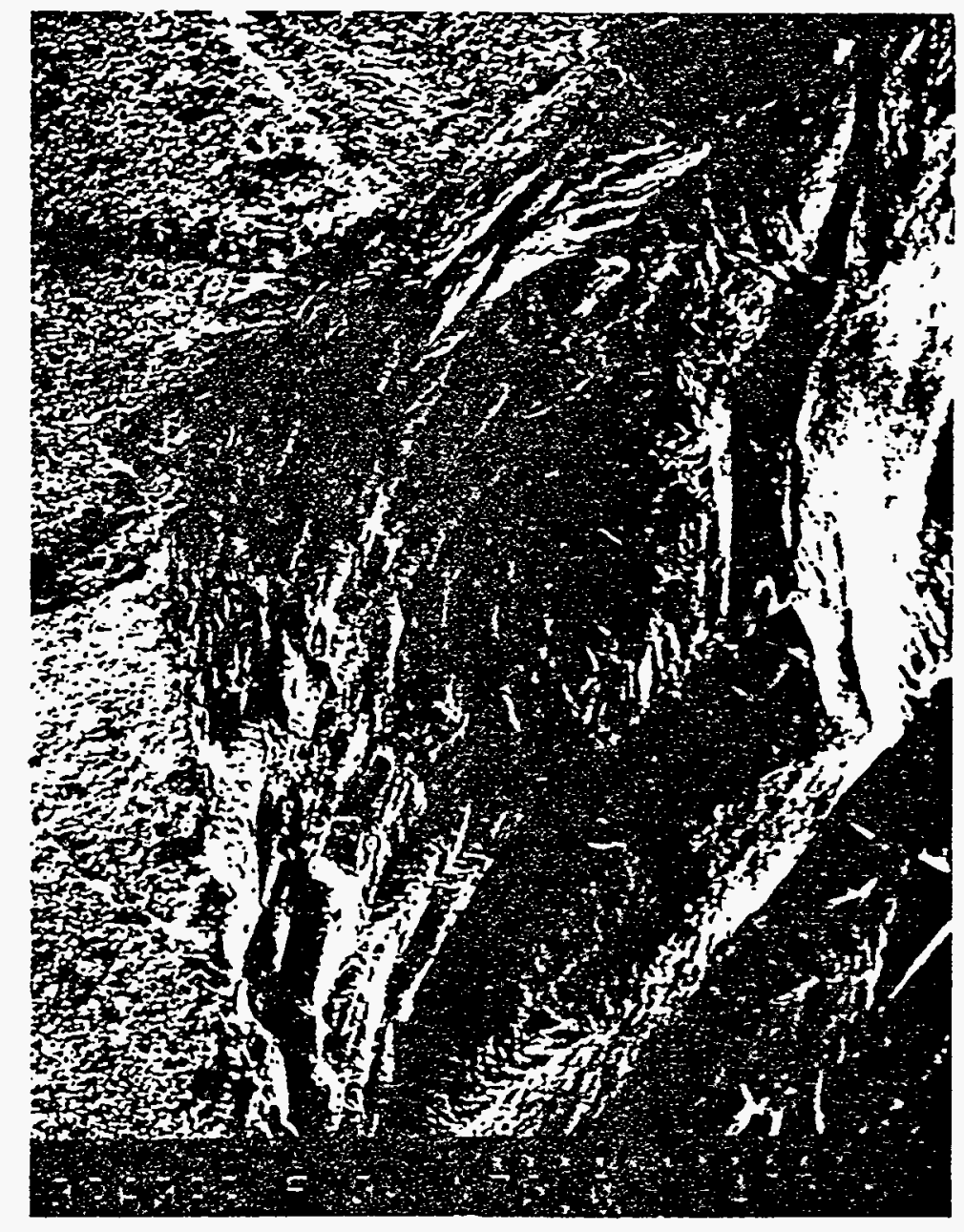

Figure $3 \mathrm{~b}$ ) The possible initiation point was a crack of approximately 1.5 by $0.8 \mathrm{~mm}$. 


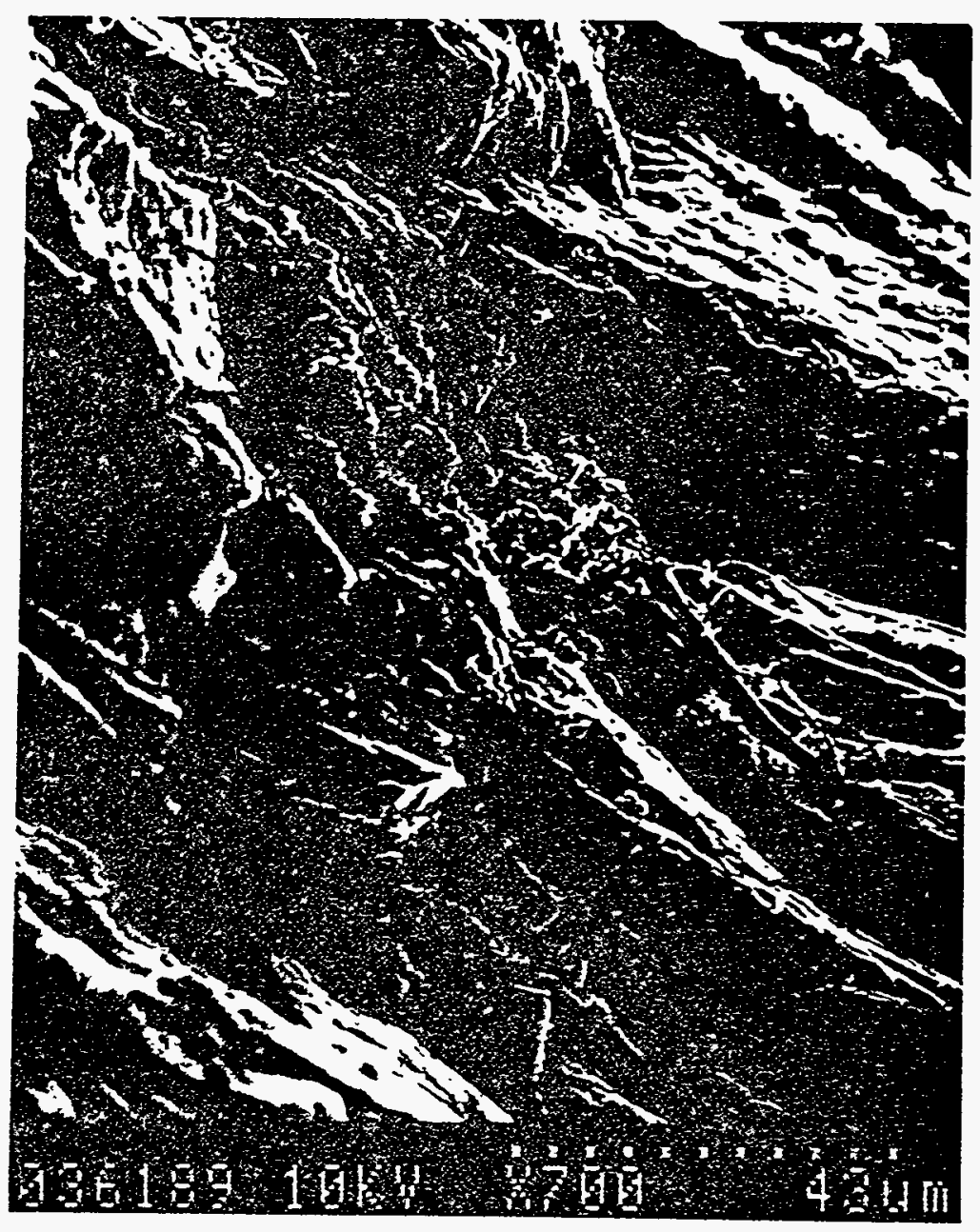

Figure 3 c) Close up of the small grained area in the crack. 


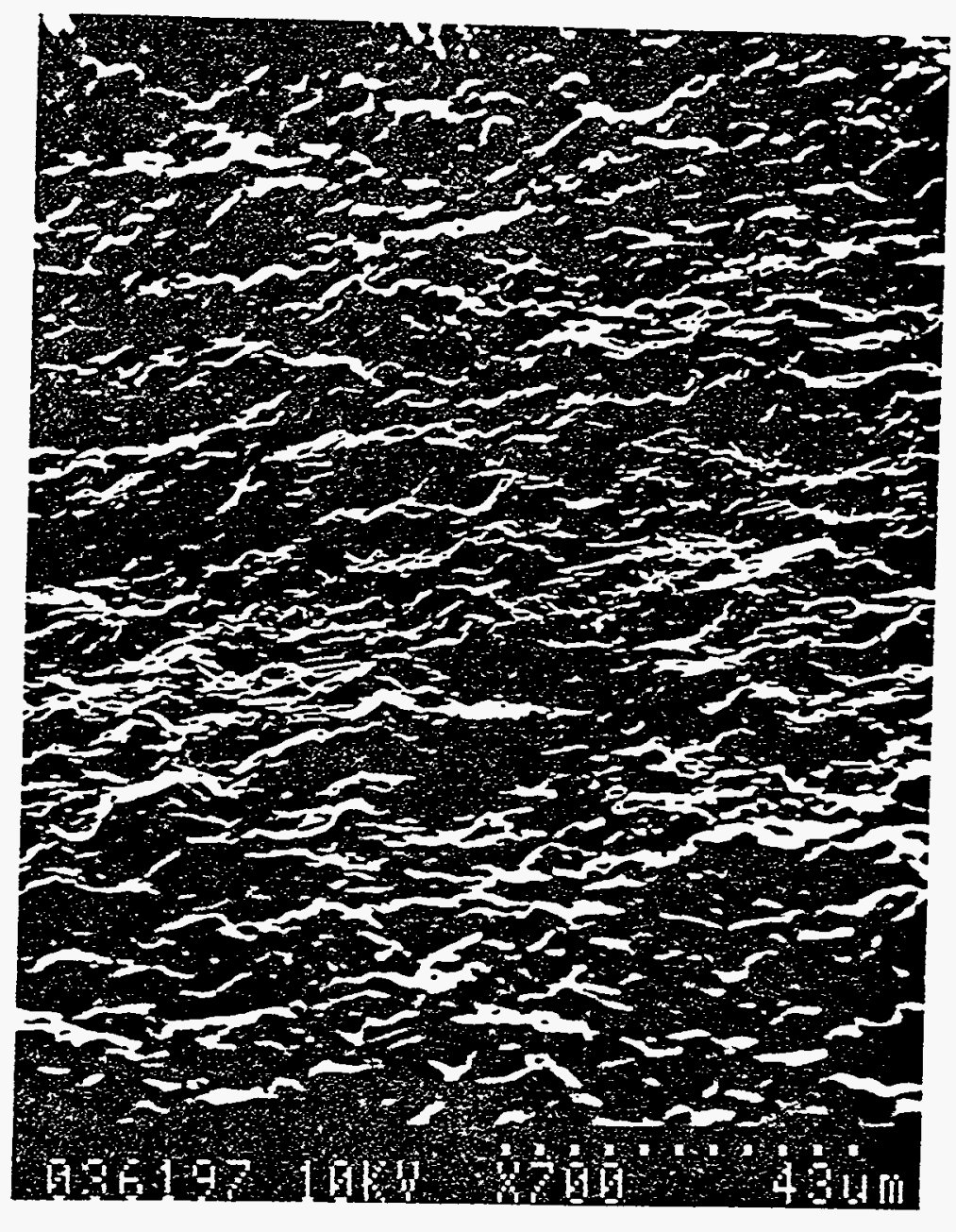

Figure 4. A clean fracture surface from fragment $\# 2$. 


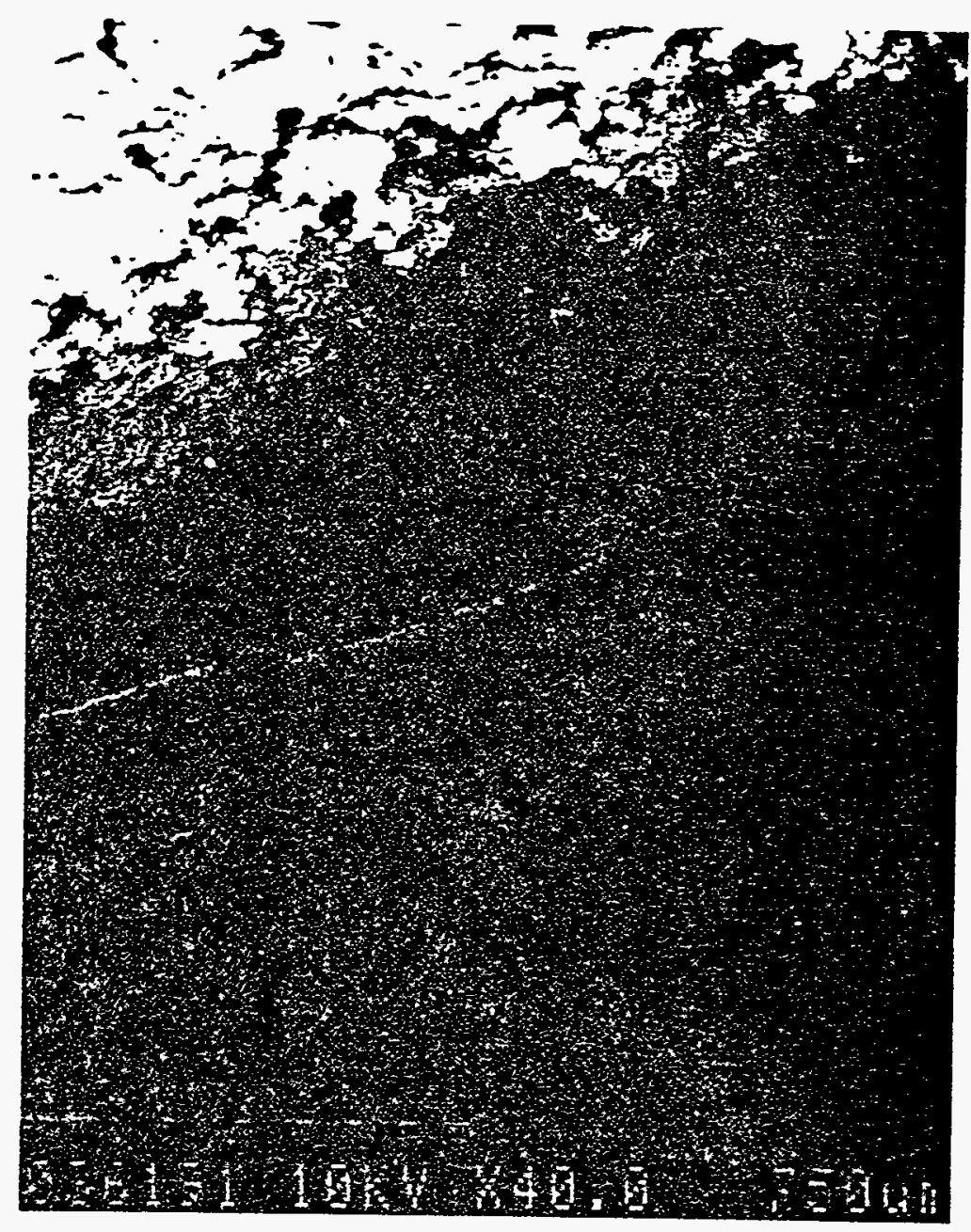

Figure 5. a) Fragment \#3 contained numerous small cracks and the surface contained an oxidation layer. 


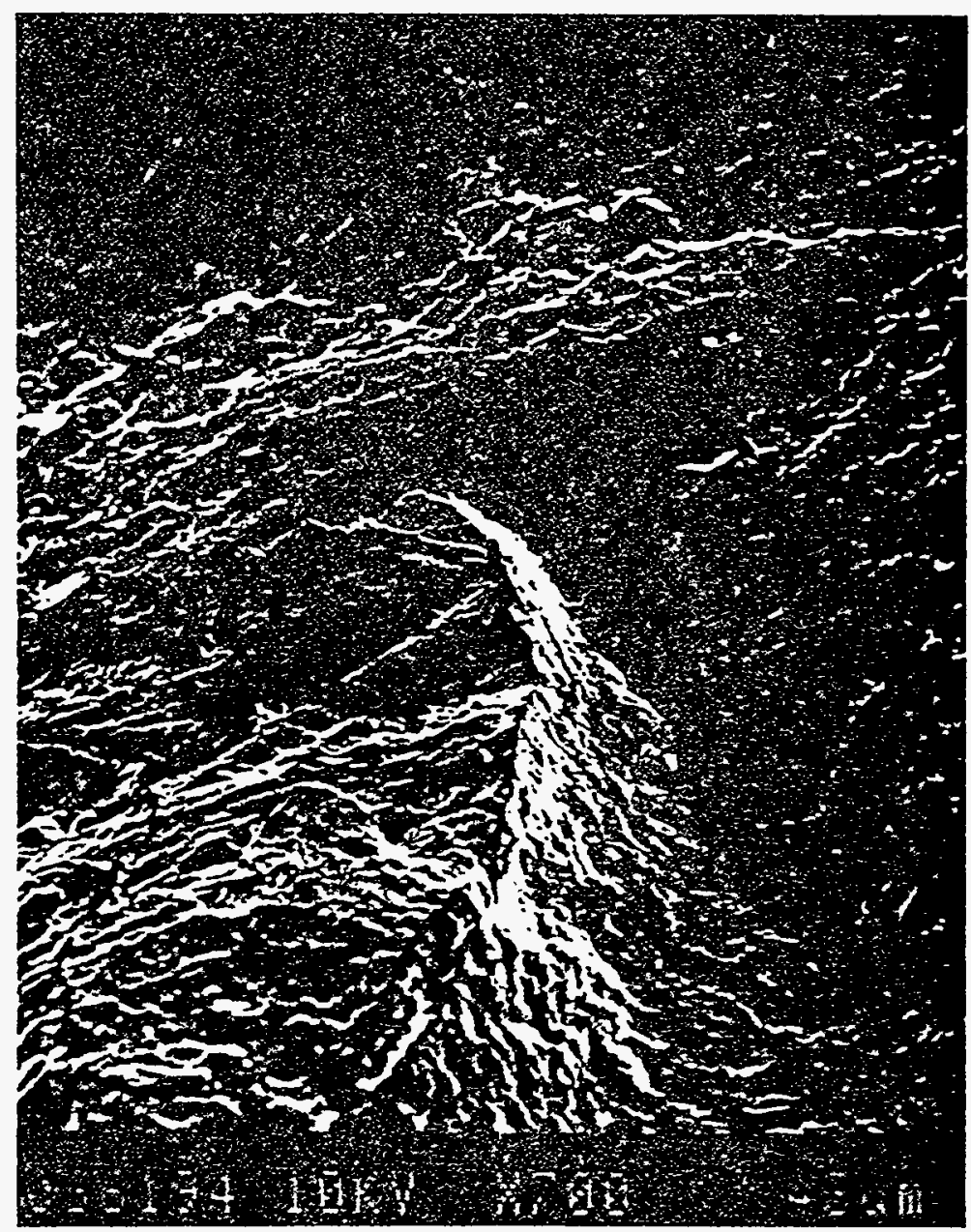

ExII: 5. b) A fracture surface from fragment \#3 containing numerous small cracks. 


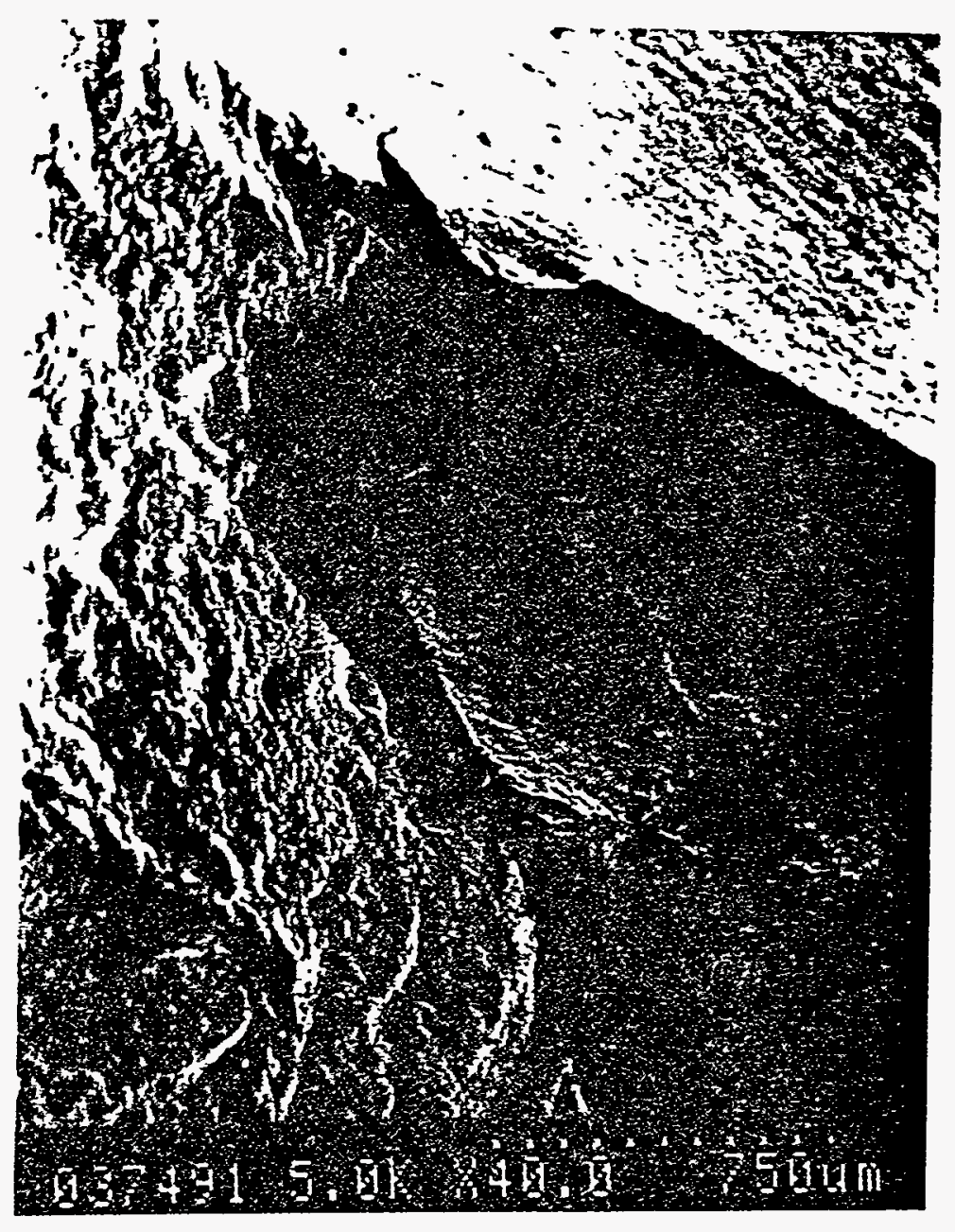

Figure 6. A possible initiation site from fragment \#4. 


\section{DISCUSSION}

The above analysis resulted in the finding of two possible failure initiating flaws. The most likely initiation point is the one located on fragment \#1 (Fig. 3), because the flaw located here was situated in the fracture pattern in a way that is typical for initiation points in tubular geometries. Further, the good correlation between the crack branching length and the flaw size indicates this as the initiation point. The calculated stress level of $77 \mathrm{MPa}$ is higher than the stresses set up in the tube due to the internal pressure of $1.4 \mathrm{MPa}(200 \mathrm{psi})$. However, if the stresses due to the temperature differences both along the length of the tube and between the inner and outer surfaces is taken into account, hoop stresses between $25 \mathrm{MPa}$ (closed end) and $100 \mathrm{MPa}$ (open end) may exist in the tube 7 and these stress levels would be high enough to initiate failure at the given circumstances.

The flaw in Fig. 3 is quite large and must have developed over time during the previous eight cycles, or the failure would have occurred at an earlier stage. Sintered $\alpha-\mathrm{SiC}$ is not prone to slow crack growth damage at temperatures which occurred under the present experiment. 8 However, the nature of the flaw is more like that of an oxidation pit, with oxide interspersed with cracks. It is possible that the cyclic stresses resulting from the thermal cycling may have caused repeated cracking of the $\mathrm{SiO}_{2}$ scale at preexisting sites like pores and thereby gradually creating a larger crack. This is consistent with the observations by Quinn and $\mathrm{Katz}^{9}$ who in a stepped temperature stress rupture test saw time dependent failure typical of slow crack growth, but they found no fractographic evidence of SCG. They indicated that oxidation of surface connected porosity might be the reason for the observed behavior. Normally under the conditions described above $\mathrm{SiC}$ will have a protective $\mathrm{SiO}_{2}$ layer produced by passive oxidation. This will protect the ceramic from further oxidation damage. Active oxidation will not occur until the oxygen partial pressure drops below approximately $13 \mathrm{MPa}\left(10^{-2} \mathrm{Tor}\right) .10$ The presence of steam in the system will however alter this value, and it is possible that further local active oxidation may be aided by the presence of material impurities. An additional complicating factor is that the oxidation behavior of $\mathrm{SiC}$ has been shown to change with the applied stress level. 11 It is not known how the stress level may affect the passive to active oxidation transition.

\section{CONCLUSIONS}

The fractographic investigation of the fractured $\mathrm{SiC}$ tube indicates that the fracture initiated from a flaw approximately $0.9 \mathrm{~mm}$ deep located at the inner tube surface approximately $170 \mathrm{~mm}$ from the bottom of the tube. The flaw contained oxide and it is assumed that the flaw developed during the previous eight temperature cycles. The oxidation could have occurred at an already existing 
pore, and might have been enhanced by the presence of steam and stress. The tube failed at a hoop stress of approximately $77 \mathrm{MPa}$, a stress which could arise from the combined action of internal pressure and thermal gradients.

\section{REFERENCES}

1. D. E. McCullum, N. L. Hecht, L. Chuck and S. M. Goodrich, "Summary of results of the Effects of Environment on Mechanical Behavior of HighPerformance Ceramics," Ceram. Eng. Sci. Proc., 12 [9-10] 1886-1913 1991.

2. V. D. Frechette, Failure Analysis of Brittle Materials, Advances in Ceramics Vol. 28, American Ceramic Society, OH 1990.

3. J. J. Mecholsky, A. C. Gonzalez and S. W. Freiman, "Fractographic Analysis of Delayed Failure in Soda-Lime Glass," J. Am. Ceram. Soc., 62 [1112] 577-580 1979.

4. J. C. Newman and I. S. Raju, "An Empirical Stress Intensity Factor Equation for the Surface Crack," Eng. Fract. Mech., 15 [1-2] 185-192 1981.

5. G. S. Glasemann, K. Jakus and J. E. Ritter Jr., " Strength and Variability of Indented Soda-Lime Glass," J. Am. Ceram. Soc., 70 [6] 441-444 1987.

6. D. L. Shellman, Personal Communication 1993.

7. D. L. Shellman, R. E. Tressler and J. C. Conway Jr., "Finite Element Analysis of Heat Exchanger Tubes," Quarterly Report to DOE under Contract No. PS-004416 between DOE and Penn State, August 1993.

8. K. Y. Chia and K. S. Lau, "High Toughness Silicon Carbide," Ceram Eng. Sci. Proc., 12 [9-10] 1845-61 1991.

9. G. D. Quinn and R. N. Katz, "Time Dependent High-Temperature Strength of Sintered $\alpha$-SiC," J. Am. Cer. Soc., 63 [1-2] 117-119 1980.

10. E. A. Gulbransen and S. A. Jansson, "The High-Temperature Oxidation, Reduction, and Volatilization Reactions of Silicon and Silicon Carbide," Oxidation of Metals, 4 [3] 181-201 1972.

11. T. E. Easler, R. C. Bradt and R. E. Tressler, "Strength Distributions of SiC Ceramics After Oxidation and Oxidation under Load," J. Am. Cer. Soc., 64 [12] 731-734 1981. 